\title{
Primary Peritoneal Cancer by AJCC v8 Stage
}

National Cancer Institute

\section{Source}

National Cancer Institute. Primary Peritoneal Cancer by A/CC v8 Stage. NCI Thesaurus.

Code C140004.

A term that refers to the staging of primary peritoneal cancer according to the American Joint Committee on Cancer, 8th edition. 